\title{
Goods that are good enough: Introducing an absolute sustainability perspective for managing chemicals in consumer products
}

\author{
Fantke, Peter; IIIner, Nicole
}

Published in:

Current Opinion in Green and Sustainable Chemistry

Link to article, DOI:

10.1016/j.cogsc.2018.12.001

Publication date:

2019

Document Version

Peer reviewed version

Link back to DTU Orbit

Citation (APA):

Fantke, P., \& Illner, N. (2019). Goods that are good enough: Introducing an absolute sustainability perspective for managing chemicals in consumer products. Current Opinion in Green and Sustainable Chemistry, $15,91-97$. https://doi.org/10.1016/j.cogsc.2018.12.001

\section{General rights}

Copyright and moral rights for the publications made accessible in the public portal are retained by the authors and/or other copyright owners and it is a condition of accessing publications that users recognise and abide by the legal requirements associated with these rights.

- Users may download and print one copy of any publication from the public portal for the purpose of private study or research.

- You may not further distribute the material or use it for any profit-making activity or commercial gain

- You may freely distribute the URL identifying the publication in the public portal 


\section{Accepted Manuscript}

Goods that are good enough: Introducing an absolute sustainability perspective for managing chemicals in consumer products

Peter Fantke, Nicole IIIner

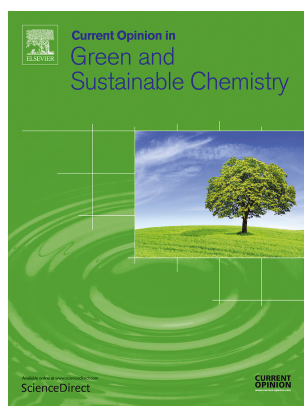

PII:

S2452-2236(18)30073-7

DOI: https://doi.org/10.1016/j.cogsc.2018.12.001

Reference: COGSC 236

To appear in: Current Opinion in Green and Sustainable Chemistry

Received Date: 9 July 2018

Revised Date: 22 November 2018

Accepted Date: 1 December 2018

Please cite this article as: P. Fantke, N. Illner, Goods that are good enough: Introducing an absolute sustainability perspective for managing chemicals in consumer products, Current Opinion in Green and Sustainable Chemistry, https://doi.org/10.1016/j.cogsc.2018.12.001.

This is a PDF file of an unedited manuscript that has been accepted for publication. As a service to our customers we are providing this early version of the manuscript. The manuscript will undergo copyediting, typesetting, and review of the resulting proof before it is published in its final form. Please note that during the production process errors may be discovered which could affect the content, and all legal disclaimers that apply to the journal pertain. 
1 Goods that are good enough: Introducing an absolute sustainability

2 perspective for managing chemicals in consumer products

3 Peter Fantke ${ }^{1} *$, Nicole Illner ${ }^{1}$

4

$5 \quad{ }^{1}$ Division for Quantitative Sustainability Assessment, Technical University of Denmark,

6 Diplomvej 371, 2800 Kgs. Lyngby, Denmark

7

$8 \quad *$ Corresponding author: phone: +45 45254452, email: pefan@ dtu.dk

9

10 


\section{Abstract}

While many products become more sustainable, overall pressure from emissions and exposure to chemicals in products on human and environmental health increases, driven by worldwide growing chemical and product diversity and consumption. To benchmark environmental sustainability performance of new products and measure related progress, we need to move from eco-efficiency indicating relative improvements to eco-effectiveness linking chemical-related impacts to absolute sustainability limits, considering entire chemical and product life cycles. Efforts in chemical substitution and alternatives assessment to replace harmful chemicals with sustainable solutions are still in their infancy and lack applicability to product scales. Novel and innovative methods are required to understand the different life cycles, to quantify and link impacts associated with chemical-related product design decisions to actual limits for human and environmental health, and to integrate this absolute perspective in chemical substitution practice. With such methods at hand, it will be possible to develop products that are environmentally sustainable in an absolute scale.

\section{Introduction}

World population, per-capita consumption, and product diversity are continuously growing around the world. With that, also the synthesis, production and use of a growing variety of chemicals in consumer products from personal care to building materials is increasing and a main driver of global economic growth and innovation in product development. In 2013, the chemical sector required the extraction of more than 1.5 billion tonnes of fossil and refinery-based resources, and almost 1 billion tonnes of secondary reactants $[1 \bullet]$. This corresponds to roughly $5-10 \%$ of the resources that are extracted globally as feedstock for fueling the production and consumption of chemicals, mainly basic chemicals (e.g. plastic polymers, fertilizers, and fibers), specialty chemicals (e.g. dyes and pigments, pesticide active ingredients, and food additives), and consumer chemicals (e.g. detergents, 
soaps, fragrances and household chemicals) $[1,2]$. With that, chemicals constitute an important building block for the diversity and functionality of the wide range of our consumer products and materials. However, the use of tens of thousands commercially relevant chemicals also induces severely increasing environmental pollution and health concerns associated with chemical emissions and exposures from local to global scale $[3,4]$. Thereby, chemical pollution potentially arises in all stages of material and product life cycles from the chemicals and manufacturing industries utilizing the chemicals in their products and releases during the use stage, and disposal of the products in which the chemicals are used. Of special concern are exposures to hazardous chemical product constituents, such as certain metals, highly fluorinated compounds, flame-retardants, antimicrobial agents, bisphenols, phthalates, and certain solvents that are found in a variety of daily consumer goods [4-6•]. Efficient, effective and innovative approaches in chemical substitution are required more than ever to overcome this unsustainable and increasingly unmanageable trend related to chemicals. In order to address this challenge, the United Nations' Global Environmental and Chemical Outlooks [2,7], the OECD's Environmental Strategy and Outlook [8,9], and the Europe's Non-Toxic Environment Strategy [10•] all declare an urgent need for much greater reduction of harmful chemicals in products. However, methodologies to effectively reduce chemical emissions and exposures at the global level are still lacking, rendering chemical pollution still one of the main concerns related to impacts on human health [11] and on ecosystem functioning [12]. Instead, most environmental sustainability-related efforts focus on relative (and often marginal if at all any) improvements per product unit, while the number of product units is steadily increasing — ultimately further fostering a production trend that is unsustainable for our global environment $[13 \bullet \bullet, 14]$.

Yet, what is sustainable enough and how can we achieve it? To answer these questions in support of developing actually (i.e. absolutely) sustainable products, we need to address three main aspects and relate relevant sustainability assessment efforts in chemical 
substitution and alternatives assessment, where viable alternatives to harmful chemicals in products and processes are identified and evaluated. First, we need to understand the complex interaction of chemical and product life cycles, and quantify all environmental impacts associated with the use of chemicals. Second, we need to identify the right environmental sustainability targets based on human and ecological health capacities, and define metrics that allow us to measure progress toward meeting these targets, thereby considering product-, company-, and region-specific boundary conditions. Third and last, we need to develop comprehensive and informative approaches for chemical substitution used by practitioners and product designers for successfully identifying viable solutions that can serve as absolute environmentally sustainable alternatives to currently used harmful chemicals in products [6]. In the following, we discuss the way forward for addressing these three aspects to pave a possible road toward products that are 'good enough', i.e. environmentally sustainable in absolute terms, with first focus on environmental sustainability.

\section{From chemical to product life cycles and their environmental sustainability}

$$
\text { Chemicals are intimately linked to the societal services provided by products and }
$$
materials, since they fulfill specific performance functions as basic material constituents and formulation ingredients. Furthermore, chemicals are used for auxiliary processes required along the wider realm of product life cycles, such as extraction, processing, or removal agents. Hence, a life cycle perspective is necessary in any chemical substitution and alternatives assessment context in order to identify and minimize exposure of humans and ecosystems to harmful chemicals along consumer product life cycles $[15,16]$. This perspective is well aligned with the circular economy, where it is mostly applied to optimize resource efficiency and waste handling [17], while the optimization of chemical-related impacts that predominantly occur before a product's end-of-life stage are just recently gaining attention. Applying a life cycle perspective, however, requires to clearly differentiating the life cycle of 
a chemical — the focus of the European REACH regulation [18] — from the life cycle of a

product or product system. While tens to hundreds of chemicals are usually involved in a product life cycle, a chemical, polymer or material can also enter several product life cycles through e.g. increased recycling of polymer waste (Figure 1).

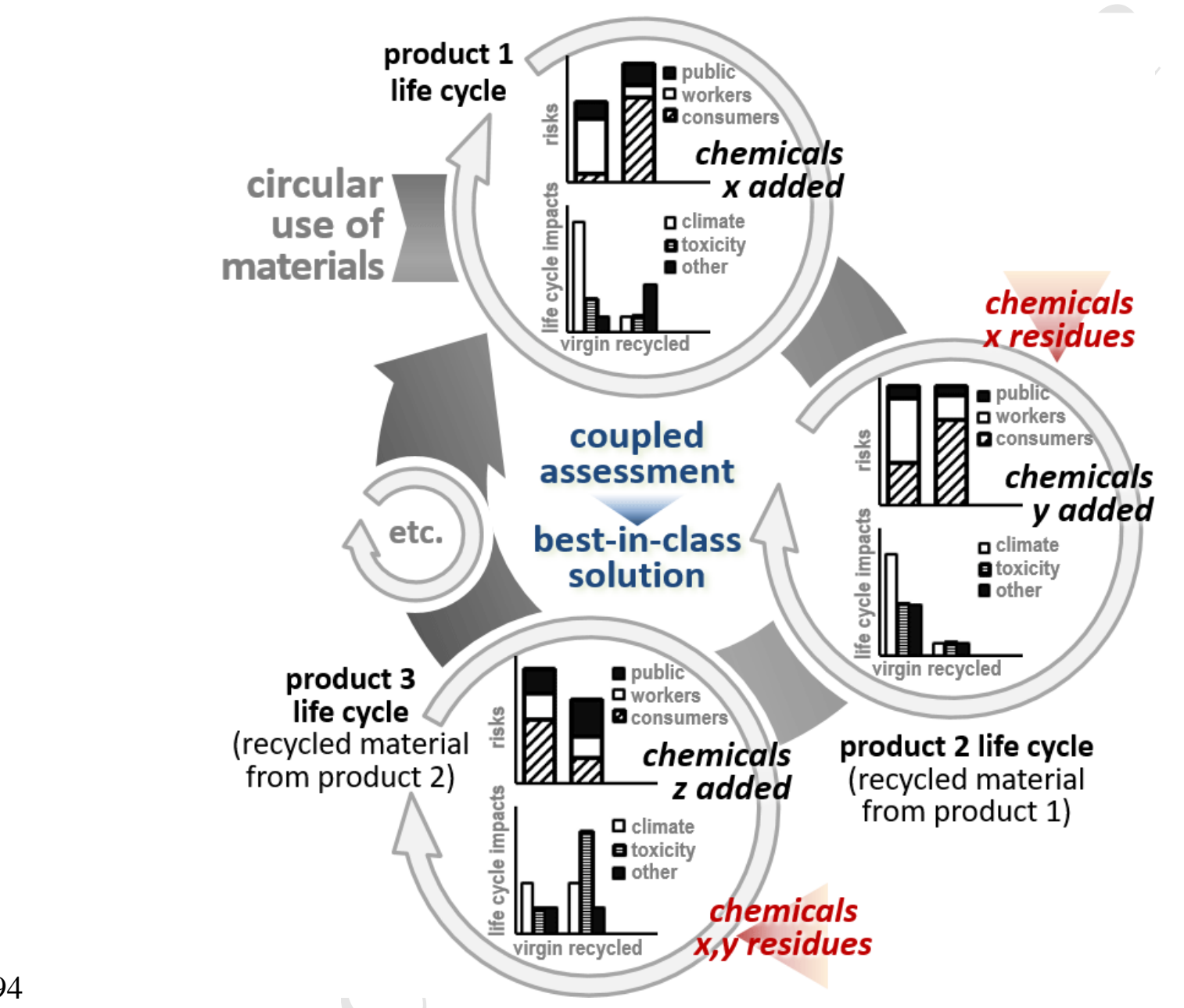

Figure 1. Assessment framework for alternative materials entering multiple product life cycles, where elements from safety and from sustainability assessment are coupled in a consistent way using comparative and quantitative metrics to identify and minimize trade-offs long the entire chemical life cycle and value chain. 
102 for a sustainable society on the other hand require a clear definition of interfaces between

103 chemical, material, and product life cycles. In this context, evaluating chemical or material

104 life cycles that span over several product life cycles comes with challenges that are not yet

105 fully understood. One often-discussed challenge is cross-contamination from toxic residues.

106 Recent studies have shown that hazardous chemical residues are found in recycled food

107 contact materials $[19,20]$, but also in other products containing recycled materials, such as

108 children's toys [21] or other plastics [22]. There is a need to include cross-contamination as

109 potential trade-off when designing a recyclable product. More generally, the concept of a

110 circular economy can only be successful, if we are able to incorporate in product design

111 decisions all relevant optimization requirements for different levels of circularity. For reuse,

112 this includes to assess increased exposure duration versus reduced resources extraction. For

113 recycling, the introduction of cross-contamination, potentially increased exposures and new

114 exposure settings to residual chemicals in recycled materials (see Figure 1), and increased

115 energy, water and resources use for additional recycling processes versus decrease in

116 resources extraction should be assessed. For repairing, it is relevant to address increased

117 energy, water and material use for spare parts and repair work versus decrease in resource

118 extraction and waste. For remanufacturing, this includes assessing increased exposure to

119 additional materials versus decrease in manufacturing energy use and waste. A sustainable

120 way out of the challenges around the use of harmful chemicals in products, especially in a

121 circular economy context, should not only be restricted to analyze the option of using drop-in

122 chemicals as potential alternatives (i.e. structurally similar chemicals), which may yield

123 similarly harmful or unsustainable performance. Instead, for successfully addressing these

124 challenges, we also need to explore technical (e.g. new barriers in packaging materials to

125 reduce migration into food matrices) and conceptual (e.g. safe-by-design) solutions. In this

126 context, it is important to look beyond particular hazards or exposure conditions. 
When addressing harmful chemicals in products in a regulatory context, occupational,

128 consumer, population and even ecological exposures and hazards are separately considered

$129[18,23,24]$, while potential trade-offs among them and with environmental sustainability

130 impacts along the entire related product life cycle are ignored. However, only when both

131 specific risks and sustainability impacts are addressed together for each product life cycle as

132 illustrated in Figure 1, we are able to avoid shifting the burden from one aspect or region to

133 another in our attempt to identify viable solutions in chemical substitution and alternatives

134 assessment [25]. Applying this to the thousands of chemicals currently in commerce is not a

135 simple task and requires prioritization of the most contributing chemicals and impacts along

136 the considered life cycles [26]. However, even when considering all trade-offs, how can we

137 ensure that the proposed product solutions are good enough? For that, it is in principle

138 necessary to identify chemical exposure and pollution benchmark targets and define for each

139 target a limit, beyond which a product is not sustainable anymore [27••].

Identifying absolute sustainability targets for chemicals and measuring related progress

Several targets defined in the United Nations' Sustainable Development Goals are

143 related to reducing chemical pollution and exposure by 2020 or 2030 [28]. These targets can

144 be used to benchmark emission and exposure levels. At the global scale, another conceptual

145 framework can be used for benchmarking, namely the planetary boundaries, which indicate a

146 'safe operating space' for our society [29]. However, local-to-regional boundaries still need to

147 be identified, and control variables for specifying a 'safe operating space' for chemical

148 pollution remain to be defined [30]. Such control variables should for ecosystems be rooted in

149 ecological carrying capacities that define benchmark exposure levels below which ecosystems

150 are not irreversibly damaged [31•], and for humans in the capacity of nations to avoid human

151 disease burden based on improving the availability, accessibility and quality of health care

$152[32 \bullet]$. 
While targets can be defined based on different reference points, methods for

154 allocating these targets to the performance of a particular product or product system also need

155 to be developed, accounting for the overall production quantity and regional differences in

156 related ecological carrying capacities. Assessing sustainability at product level (and not just at

157 the level of nations, cities or companies) is important, since it is not straightforward to go

158 from the global level to the product level and a number of assumptions and choices are

159 required to properly scale down sustainability impacts as well as related carrying capacities

160 and allocate both to individual products. Product-level sustainability assessment could help

161 both companies to decide what is needed in terms of improvement of specific products and

162 consumers to judge the types and level of consumption that can be considered sustainable

163 [33]. Linking ecological carrying capacities to absolute sustainability targets is an emerging

164 research field, starting with a seminal paper on gauging industrial sustainability [13], followed

165 since by a series of about 20-30 studies linking life cycle impacts to planetary boundaries and

166 other absolute sustainability targets [34-37]. This research indicates that environmental

167 impacts of economic activities need to be aligned with the continuous functioning of the life-

168 sustaining services of nature, i.e. we need to reduce unit resource consumption and

169 environmental emissions and exposure to an extent that allows us to stay within an actually

170 sustainable space, i.e. within a 'safe operating space'.

171 This is illustrated in Figure 2, where for any product or product system $\mathbf{A}$ the different

172 environmental impacts (1) and (2) are quantified (left bars) that cumulatively exceed a related

173 absolute sustainability target (dashed horizontal line), and where a design choice leads to

174 product or product system B (right bars) with its different cumulative impacts. Three

175 archetypal scenarios are possible. First, impacts in each category (e.g. human toxicity, air

176 pollution, ecotoxicity) change but both products exceed absolute targets, which usually comes

177 with shifting the burden from one impact category to another (Figure 2, top plot). Second,

178 impacts in one or more categories are reduced while others remain constant, leading 
179 cumulatively to overall impact reduction without burden shifting, which still exceeds (to a

180 lesser extent now) absolute targets (Figure 2, middle plot). Third, impacts in one or more

181 categories are reduced without burden shifting and cumulatively to the extent that absolute

182 targets are met (Figure 2, bottom plot). The last scenario is the only one that will ultimately

183 lead to absolutely sustainable products and is hence the only desirable scenario in line with

184 sustainability goals.

185

Burden shifting,

$A$ and $B$ unsustainable

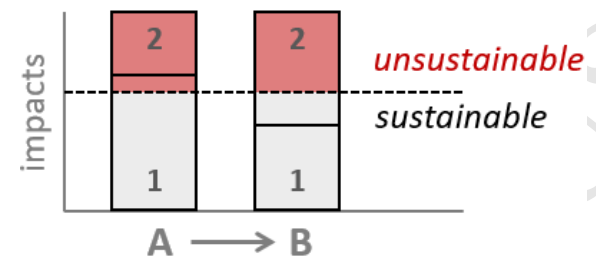

No burden shifting,

$A$ and $B$ unsustainable

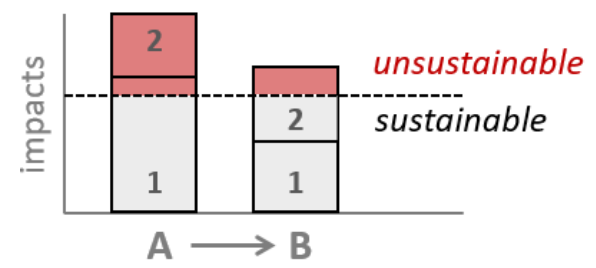

No burden shifting,

B sustainable

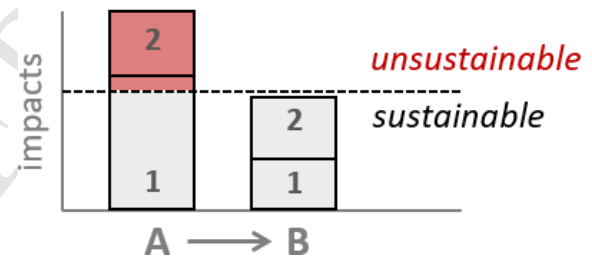

187 Figure 2. Illustration of different scenarios of burden shifting between impacts or life cycle

188 stages or regions (1) and (2) and relation to absolute sustainability targets between product

189 solutions or product design choices (A) and (B). An example for such burden shifting is to

190 replace a harmful chemical in a consumer product to reduce consumer risk, while the

191 substitute has a more complex synthesis, thus leading to higher manufacturing energy use and

192 related emissions (top and middle graphs). In this example, the original harmful chemical 
would need to be replaced by an alternative that does also not lead to increased environmental

194 impacts in manufacturing in order to become sustainable (bottom graph).

When absolute sustainability targets are defined, the related performance of designed

197 products or product systems needs to be quantified and compared against these targets in

198 order to identify whether a design choice or one of its alternatives stays within the

199 sustainability domain (see Figure 2). For that, both quantifiable sustainability performances and related absolute targets need to be considered in chemical substitution and alternatives assessment frameworks that are applied by product designers and other decision makers to evaluate different alternatives and identify the 'best-in-class' solution. How are these aspects considered in chemical substitution and alternatives assessment practice today? In the following section, we discuss this question.

\section{Alternatives assessment: Solutions for substituting harmful chemicals in products}

Currently, environmental sustainability aspects are mostly considered as secondary

goal and late in the technology readiness stages [38], whereas assessing related trade-offs and measuring performance against absolute targets will have the highest effect at early product design stages. To evaluate 'best-in-class' options among various alternatives at early design stages, alternatives assessment and chemical substitution are ideal rapid-screening level tools $[6,39]$, which ideally compare alternatives to harmful chemicals in products and processes based on a common function or societal service [40•]. Existing alternatives assessment

214 frameworks, however, focus mostly on hazard, and technical and economic feasibility, while environmental sustainability aspects and an absolute perspective are not considered. This renders current assessment results unable to support chemical and product design in relation mostly relies on qualitative or categorical metrics $[41,42]$. However, to successfully minimize 
trade-offs and measure performance progress against absolute sustainability targets,

comparative metrics (to allow for comparison of environmental sustainability impacts and

their respective absolute targets) and quantitative yet rapid-screening assessment approaches

are required (to allow for quantitatively identifying and minimizing tradeoffs e.g. in exposure

settings) $[42,43]$.

Using such approaches, specific exposure settings for workers and consumers need to

be consistently combined with population exposures from environmental life cycle emissions

and related absolute targets. This is important in order to go beyond marginal improvements

in product design, which could result from improving a certain exposure aspect, while

approach introducing comparative metrics and quantitative, rapid-screening level assessment,

230 a high-throughput framework has been recently proposed that on the one hand integrates

different exposures and populations, while on the other hand being compatible with the

alternatives assessment framework $[44 \bullet \bullet, 45]$. This exposure assessment framework has been

[47], personal care products [48], and building materials [49], and can be expanded based on

models to cover additional product types [50]. Along with additional models, also exposure

and hazard data are required for all considered alternatives, be it chemicals or other solutions,

such as of material, technological, or behavioral nature. However, this constitutes a current

challenge, since for example adequate exposure-response information is available usually

only for a handful of well-studied chemicals [51], while largely missing for most of less-

studied chemicals in global commerce and hence also missing in estimates of human disease

burden. Promising solutions to be explored are high-throughput methods to screen exposure

[52•] and toxicity across a wide range of chemicals [53•]. 
245 limited capacity of our sustaining ecological and health systems is already widely

246 acknowledged [54-59], quantitative metrics for absolute targets and for measuring related

247 progress toward meeting these targets still need to be developed. In support of such metrics,

248 some studies relate chemical pollution to regulatory concentration thresholds [60-63], but

249 these do usually not reflect actual and regionally varying carrying capacities. Hence, while

250 first attempts to link absolute sustainability targets to product life cycles exist, further efforts

251 are required to systematically developing methods for introducing an absolute perspective

252 also in alternatives assessment and green chemistry.

\section{Conclusions}

While products are becoming more sustainable, we also need to reduce overall chemical-related pressure on human and environmental health. This requires moving from relative and marginal improvements as assessed in current life cycle assessments to applying an absolute sustainability perspective that allows measuring progress toward relevant limits for chemical pollution and exposure at various scales. Chemical substitution and alternatives assessment to replace harmful chemicals with sustainable solutions are emerging and promising frameworks, into which an absolute sustainability perspective should be introduced. This requires a deep understanding of the complex interaction of different chemical, material and product life cycles, novel methods to quantify and link chemicalrelated impacts to actual limits for human and environmental health, and to integrate these methods in chemical substitution practice. Once such methods are becoming available, it will

266 be possible to develop products that are environmentally sustainable in an absolute scale, i.e. designing and developing goods that are good enough.

\section{Acknowledgements}

270 We thank Michael Hauschild for valuable comments on an earlier manuscript version. 


\section{References}

273

Papers of particular interest, published within the period of review, have been highlighted as:

- Of special interest

•• Of outstanding interest

1. Levi PG, Cullen JM: Mapping global flows of chemicals: From fossil fuel feedstocks to - chemical products. Environmental Science and Technology 2018, 52:1725-1734.

Based on a complete mass balance, the authors comprehensively and transparently map for the year 2013 the global chemical mass flows from fossil fuel feedstocks to chemical products through a complex network of transformation processes, also considering secondary reactants and by-products.

2. United Nations Environment Programme: Global Chemicals Outlook - GCO: Towards Sound Management of Chemicals. Geneva, Switzerland; 2013.

3. Bernhardt ES, Rosi EJ, Gessner MO: Synthetic chemicals as agents of global change. Frontiers in Ecology and the Environment 2017, 15:84-90.

4. Grandjean P, Bellanger M: Calculation of the disease burden associated with environmental chemical exposures: Application of toxicological information in health economic estimation. Environmental Health 2017, 16:123.

5. Blum A: Tackling toxics. Science 2016, 351:1117-1117.

6. Fantke P, Weber R, Scheringer M: From incremental to fundamental substitution in - chemical alternatives assessment. Sustainable Chemistry and Pharmacy 2015, 1:1-8.

A seminal paper, in which the authors outline current challenges and opportunities for phasing out hazardous chemicals at the global scale including an overview over well-recognized examples and a roadmap for a fundamental improvement of current substitution practice based on an integrated stakeholder approach.

7. United Nations Environment Programme: Global Environmental Outlook - GEO 6: Assessment for the Pan European region. Nairobi, Kenya; 2016.

8. Organisation for Economic Co-operation and Development: Review of the Implementation of the OECD Environmental Strategy for the First Decade of the $21^{\text {st }}$ Century. Paris: Organisation for Economic Co-operation and Development; 2012.

9. Organisation for Economic Co-operation and Development: OECD Environmental Outlook to 2050. Paris: Organisation for Economic Co-operation and Development; 2012.

10. European Commission: Study for the strategy for a non-toxic environment of the 7th

- Environment Action Programme: Final Report. Brussels, Belgium; 2017. 
In this report published by the European Commission, the authors lay the foundation for a Union strategy for a non-toxic environment that is conducive to innovation and the development of sustainable substitutes to harmful chemicals with focus on addressing grouping of chemicals, chemicals in articles, children's exposure, very persistent chemicals, policy innovation, new non-toxic chemicals, and early warning systems.

11. Landrigan PJ, Fuller R, Acosta NJR, Adeyi O, Arnold R, Basu N, Baldé AB, Bertollini R, Bose-O'Reilly S, Boufford JI, et al.: The Lancet Commission on pollution and health. The Lancet 2018, 391:462-512.

12. Secretariat of the Convention on Biological Diversity: Global Biodiversity Outlook 3. Edited by. Montréal; 2010.

13. Hauschild MZ: Better - But is it good enough? On the need to consider both eco-

-• efficiency and eco-effectiveness to gauge industrial sustainability. Procedia CIRP 2015, 29:1-7.

A seminal paper, in which the author proposes a way to move current eco-efficiency approaches focusing on increasing sustainability per production unit to eco-effectiveness also accounting for the growth in population, affluence and per-capita consumption for achieving sustainable production in absolute terms.

14. Steffen W, Broadgate W, Deutsch L, Gaffney O, Ludwig C: The trajectory of the Anthropocene: The great acceleration. The Anthropocene Review 2015, 2:81-98.

15. Hauschild MZ: Assessing environmental impacts in a life-cycle perspective. Environmental Science and Technology 2005, 39:81A-88A.

16. Fantke P, Ernstoff A: LCA of chemicals and chemical products. In Life Cycle Assessment: Theory and Practice. Edited by Hauschild M, Rosenbaum RK, Olsen SI: Springer International Publishing; 2018:783-815.

17. Stahel WR: The circular economy. Nature 2016, 531:435-438.

18. European Commission: Regulation (EC) No 1907/2006 of the European Parliament and of the Council of 18 December 2006 concerning the Registration, Evaluation, Authorisation and Restriction of Chemicals (REACH). Brussels; 2006.

19. Biedermann M, Grob K: Assurance of safety of recycled paperboard for food packaging through comprehensive analysis of potential migrants is unrealistic. Journal of Chromatography 2013, 1293:107-119.

20. Pieke EN, Smedsgaard J, Granby K: Exploring the chemistry of complex samples by tentative identification and semiquantification: A food contact material case. Journal of Mass Spectrometry 2018, 53:323-335.

21. Chen S-J, Ma Y-J, Wang J, Chen D, Luo X-J, Mai B-X: Brominated flame retardants in children's toys: Concentration, composition, and children's eposure and risk assessment. Environmental Science and Technology 2009, 43:4200-4206. the circular economy - weeding out the toxics first. Environment International 2016, 94:230-234. 
23. European Commission: Regulation (EC) No 1272/2008 of the European Parliament and of the Council of 16 December 2008 on classification, labelling and packaging of substances and mixtures. Brussels; 2008.

24. Giubilato E, Pizzol L, Scanferla P, Faggian V, Critto A, Semenzin E, Marcomini A: Comparative occupational risk assessment to support the substitution of Substances of Very High Concern: Alternatives assessment for diarsenic trioxide in Murano artistic glass production. Journal of Cleaner Production 2016, 139:384-395.

25. Sexton K, Linder SH: Integrated assessment of risk and sustainability in the context of regulatory decision making. Environmental Science and Technology 2014, 48:14091418.

26. Halpaap A, Dittkrist J: Sustainable chemistry in the global chemicals and waste management agenda. Current Opinion in Green and Sustainable Chemistry 2018, 9:2529.

27. Bjørn A, Margni M, Roy P-O, Bulle C, Hauschild MZ: A proposal to measure absolute •• environmental sustainability in life cycle assessment. Ecological Indicators 2016, 63:113.

The authors propose a novel concept for measuring absolute sustainability in a spatially explicit life cycle perspective based on a set of indicators using environmental carrying capacities as reference, including an overview of necessary research to refine the underlying indicators.

28. United Nations: Sustainable Development Goals. 2018.

29. Steffen W, Richardson K, Rockström J, Cornell SE, Fetzer I, Bennett EM, Biggs R, Carpenter SR, de Vries W, de Wit CA, et al.: Planetary boundaries: Guiding human development on a changing planet. Science 2015, 347:736-746.

30. Diamond ML, de Wit CA, Molander S, Scheringer M, Backhaus T, Lohmann R, Arvidsson R, Bergman $\AA$, Hauschild M, Holoubek I, et al.: Exploring the planetary boundary for chemical pollution. Environment International 2015, 78:8-15.

31. Bjørn A, Hauschild MZ: Introducing carrying capacity-based normalisation in LCA:

- Framework and development of references at midpoint level. The International Journal of Life Cycle Assessment 2015, 20:1005-1018.

Based on defining ecological carrying capacities as the maximum sustained environmental intervention a natural system can withstand without experiencing negative changes in structure or functioning that are difficult or impossible to revert, the authors link environmental pressure to ecological limits and put both into a life cycle assessment context.

32. Weidema BP, Fantke P: Relating the global burden of disease to life cycles. Procedia - CIRP 2018, 69:417-422.

The authors synthetically identify that global life cycle impacts only contribute less than $10 \%$ to the global human disease burden expressed as lost lifetime and propose an approach for allocating the remaining disease burden to additional technological processes, unavoidable burden, and an insufficient health care system.

33. Kara S, Hauschild MZ, Herrmann C: Target-driven life cycle engineering: Staying within the Planetary Boundaries. Procedia CIRP 2018, 69:3-10. 
34. Bjørn A, Diamond M, Owsianiak M, Verzat B, Hauschild MZ: Strengthening the link between life cycle assessment and indicators for absolute sustainability to support development within planetary boundaries. Environmental Science and Technology 2015, 49:6370-6371.

35. Brejnrod KN, Kalbar P, Petersen S, Birkved M: The absolute environmental performance of buildings. Building and Environment 2017, 119:87-98.

36. Chandrakumar C, McLaren SJ: Towards a comprehensive absolute sustainability assessment method for effective Earth system governance: Defining key environmental indicators using an enhanced-DPSIR framework. Ecological Indicators 2018, 90:577-583.

37. Ryberg MW, Owsianiak M, Clavreul J, Mueller C, Sim S, King H, Hauschild MZ: How to bring absolute sustainability into decision-making: An industry case study using a Planetary Boundary-based methodology. Science of The Total Environment 2018, 634:1406-1416.

38. McKim AS: Overcoming sustainability barriers within the chemical industry. Current Opinion in Green and Sustainable Chemistry 2018, 14:10-13.

39. Lavoie ET, Heine LG, Holder H, Rossi MS, Lee RE, Connor EA, Vrabel MA, DiFiore DM, Davies CL: Chemical alternatives assessment: Enabling substitution to safer chemicals. Environmental Science and Technology 2010, 44:9244-9249.

40. Tickner JA, Schifano JN, Blake A, Rudisill C, Mulvihill MJ: Advancing safer

- alternatives through functional substitution. Environmental Science and Technology 2015, 49:742-749.

The authors introduce a perspective change for managing harmful chemicals in alternatives assessment by moving away from a risk-based approach to a function-based approach in order to broaden the process to go beyond chemical-by-chemical substitution.

41. Jacobs MM, Malloy TF, Tickner JA, Edwards S: Alternatives assessment frameworks: Research needs for the informed substitution of hazardous chemicals. Environmental Health Perspectives 2016, 124:265-280.

42. Greggs B, Burns T, Egeghy P, Embry M, Fantke P, Gaborek B, Heine L, Jolliet O, Lee C, Muir D, et al.: Qualitative approach to comparative exposure in alternatives assessment. Integrated Environmental Assessment and Management 2018.

43. Tickner JA, Becker M: Mainstreaming green chemistry: The need for metrics. Current Opinion in Green and Sustainable Chemistry 2016, 1:1-4.

44. Fantke P, Ernstoff AS, Huang L, Csiszar SA, Jolliet O: Coupled near-field and far-field -• exposure assessment framework for chemicals in consumer products. Environment International 2016, 94:508-518.

Based on a simple matrix approach, the authors propose a novel mass-balance based framework for consistently coupling consumer and occupational exposures (near-field) with environmentally mediated exposures (far-field) for assessing chemicals in consumer products. 
45. Jolliet O, Ernstoff AS, Csiszar SA, Fantke P: Defining product intake fraction to quantify and compare exposure to consumer products. Environmental Science and Technology 2015, 49:8924-8931.

46. Ernstoff AS, Fantke P, Csiszar SA, Henderson AD, Chung S, Jolliet O: Multi-pathway exposure modelling of chemicals in cosmetics with application to shampoo. Environment International 2016, 92-93:87-96.

47. Ernstoff AS, Fantke P, Huang L, Jolliet O: High-throughput migration modelling for estimating exposure to chemicals in food packaging in screening and prioritization tools. Food and Chemical Toxicology 2017, 109:428-438.

48. Csiszar SA, Ernstoff AS, Fantke P, Meyer DE, Jolliet O: High-throughput exposure modeling to support prioritization of chemicals in personal care products. Chemosphere 2016, 163:490-498.

49. Lanters CA, Fantke P: Structuring complex results using network maps and hierarchical charts. Procedia CIRP 2018, 69:441-446.

50. Huang L, Ernstoff A, Fantke P, Csiszar S, Jolliet O: A review of models for near-field exposure pathways of chemicals in consumer products. Science of the Total Environment 2017, 574:1182-1208.

51. Bonde JP, Flachs EM, Rimborg S, Glazer CH, Giwercman A, Ramlau-Hansen CH, Hougaard KS, Høyer BB, Hærvig KK, Petersen SB, et al.: The epidemiologic evidence linking prenatal and postnatal exposure to endocrine disrupting chemicals with male reproductive disorders: A systematic review and meta-analysis. Human Reproduction Update 2016, 23:104-125.

52. Shin H-M, Ernstoff AS, Arnot JA, Wetmore B, Csiszar SA, Fantke P, Zhang X, McKone

- TE, Jolliet O, Bennett DH: Risk-based high-throughput chemical screening and prioritization using exposure models and in vitro bioactivity assays. Environmental Science and Technology 2015, 49:6760-6771.

The authors introduce a high-throughput screening approach for predicting human exposure to chemicals in consumer products based on combining exposure models with in vitro bioactivity assays using in vitro-to-in vivo extrapolation and reverse dosimetry methods.

53. Chiu WA, Axelrad DA, Dalaijamts C, Dockins C, Shao K, Shapiro AJ, Paoli G: Beyond

- the RfD: Broad application of a probabilistic approach to improve chemical doseresponse assessments for noncancer effects. Environmental Health Perspectives 2018, 126: $1-14$.

Based on recommendations made by a WHO working group, the authors propose a novel probabilistic framework for developing stochastic dose-response models for non-cancer effects using automated and transparent extrapolation from curated animal data.

54. Bakshi BR, Ziv G, Lepech MD: Techno-ecological synergy: A framework for sustainable engineering. Environmental Science and Technology 2015, 49:1752-1760.

55. Hu S, Chen D, Jin Y, Zhu B, Ma S, Song X, Chen Z: Green development strategies for chemical industry in China: based on analysis of fertilizer industry and coal chemical industry. CIESC Journal 2014, 65:2704-2709. 
56. Brentin RP: Soy-based chemicals and materials: Growing the value chain. In SoyBased Chemicals and Materials. Edited by Brentin RP: American Chemical Society; 2014:1-23. vol 1178.]

57. Marques CA, Gonçalves FP, Yunes SF, Machado AASC: Sustentabilidade ambiental: Um estudo com pesquisadores químicos no Brasil. Química Nova 2013, 36:914-920.

58. da Silva AM: Carrying capacity in agriculture: Environmental significance and some related patents. Recent Patents on Food, Nutrition and Agriculture 2009, 1:100-103.

59. Chakrabarti T: Emergence of green technologies towards sustainable growth. In Environment and Sustainable Development. Edited by Fulekar MH, Pathak B, Kale RK: Springer India; 2014:1-21.

60. Tarasova N, Makarova A, Fantke P, Shlyakhov P: Estimating chemical footprint: contamination with mercury and its compounds. Pure and Applied Chemistry 2018, 90:857-868.

61. Bjørn A, Diamond ML, Birkved M, Hauschild MZ: Chemical footprint method for improved communication of freshwater ecotoxicity impacts in the context of ecological limits. Environmental Science and Technology 2014, 48:13253-13262.

62. Sörme L, Palm V, Finnveden G: Steps towards a national chemical footprint - using EPRTR data on point source emissions to air and water. Environmental Impact Assessment Review 2016, 56:102-112.

63. Tarasova Natalia P, Makarova Anna S, Vinokurov Stanislav F, Kuznetsov Vladimir A, Shlyakhov Pavel I: Green chemistry and sustainable development: Approaches to chemical footprint analysis. Pure and Applied Chemistry 2018, 90:143. 